Abstract

\title{
Development and Preliminary Results from the Testbed Infrastructure of the DRIP Project ${ }^{\dagger}$
}

\author{
Ioannis N. Daliakopoulos 1,2,*, Dimitrios Papadimitriou 1, Theofilos Matsoukas 2, \\ Nikolaos Zotos ${ }^{3}$, Harris Moysiadis ${ }^{3}$, Konstantinos Anastasopoulos ${ }^{3}$, Ioannis Mavrogiannis ${ }^{4}$ \\ and Thrassyvoulos Manios ${ }^{1}$ \\ 1 Department of Agriculture, Hellenic Mediterranean University, 71410 Crete, Greece; \\ dimpap@hmu.gr (D.P.); tmanios@hmu.gr (T.M.) \\ 2 Landco Ltd., 15122 Athens, Greece; tmatsoukas@landco.gr \\ 3 Future Intelligence Ltd., 15341 Athens, Greece; nzotos@f-in.gr (N.Z.); tmoysiadis@f-in.gr (H.M.); \\ kanastasopoulos@f-in.gr (K.A.) \\ 4 Anelixis Consulting SA, 71306 Heraklion, Greece; gm@anelixisc.gr \\ * Correspondence: idaliak@hmu.gr \\ † Presented at TERRAenVISION 2019, Barcelona, Spain, 2-7 September 2019.
}

Published: 20 May 2020

\begin{abstract}
Striving to tackle a common water resource scarcity problem, the Drip Irrigation Precise (DRIP) Project aims to develop a state-of-the-art integrated system that will optimize tree crop irrigation (Petousi et al. 2018). To this end, we have developed 5 free lysimeters measuring $3 \mathrm{~m}$ in height and $3 \mathrm{~m}$ in diameter, each with a total effective volume of ca. $20 \mathrm{~m}^{3}$. Lysimeters were planted with 510 -year-old olive trees, including their root ball to a depth of $1 \mathrm{~m}$, monolithically transplanted from the experimental olive orchard of the Hellenic Mediterranean University, Greece. The remaining volume was layered with soil from the same source and a gravel filter to allow leaching. Each lysimeter is equipped with IoT sensors relevant to the modeling of the soil-plant-water system; 12 measuring soil moisture, temperature, and electrical conductivity, and one measuring leachate flow. Additionally, meteorological parameters are monitored for the entire infrastructure. Sensors provide real time data to an on-line system, through a network of 15 telecommunication nodes that, together with an edge-gateway, form a local wireless 6LoWPAN mesh network, thus implementing a state-of-the-art Internet of Things (IoT) system. Experimental data collected from the lysimeters are used to model water movement using the HYDRYS 2D/3D model. Modeling output will be used for the development the commercial DRIP system, an advanced irrigation scheduler designed for the harsh conditions of the agricultural environment that utilizes feedback from environmental sensors for optimal irrigation.
\end{abstract}

Keywords: smart agriculture; Internet of Things; lysimeter; HYDRUS; soil moisture

Acknowledgments: This research has been co-financed by the European Union and Greek national funds through the Operational Program Competitiveness, Entrepreneurship and Innovation, under the call RESEARCH-CREATE-INNOVATE (project code: T1EDK-03372) [1]. 


\section{Reference}

1. Petousi, I.; Daliakopoulos, I.N.; Matsoukas, T.; Zotos, N.; Mavrogiannis, I.; Manios., T. 2018. DRIP: Development of an Advanced Precision Drip Irrigation System for Tree Crops. In Proceedings of the TerraEnVision Conference, Barcelona, Spain, 29 January-2 February 2018.

(C) 2020 by the authors. Licensee MDPI, Basel, Switzerland. This article is an open access article distributed under the terms and conditions of the Creative Commons Attribution (CC BY) license (http://creativecommons.org/licenses/by/4.0/). 